\title{
Temperamental Predictive Factors for Success in Korean Professional Baseball Players
}

\author{
Kyoung Doo Kang ${ }^{1}$, Doug Hyun Han ${ }^{\bowtie}$, James C. Hannon ${ }^{1}$, Morgan S. Hall ${ }^{1}$, and Jae Won Choi ${ }^{3}$ \\ ${ }^{1}$ Department of Exercise and Sport Science, University of Utah, Salt Lake City, UT, USA \\ ${ }^{2}$ Department of Psychiatry, Chung-Ang University Hospital, Seoul, Republic of Korea \\ ${ }^{3}$ Department of Sports, Chung-Ang University, Anseong, Republic of Korea
}

\begin{abstract}
Objective In this five-year cohort study, we hypothesize that factors of temperament and character in professional baseball players predict the speed of obtaining success and the quality of success as well as anxiety control.

Methods Participants included 120 male rookie players from the Korea Baseball Organization (KBO) and 107 male non-players with no history of playing baseball. The personality/characters and state/trait anxieties of participants were assessed with the Temperament and Character Inventory (TCI) and Spielberg's State-Trait Anxiety Inventory-Y (STAI-Y). Over the duration of five years, all the players were subsequently classified into either a success group (major leaguers) or a non-success group (non-major leaguers), depending on their status in the professional baseball league in Korea.

Results The players in the group of starters had higher novelty seeking (NS) scores than those of non-starters. The reward dependence $(\mathrm{RD})$ scores of the success group were higher than those of the non-success group. The state anxiety scores in the starter group were negatively correlated with NS scores. The state and trait anxieties in the non-success group were positively correlated with RD scores.

Conclusion The results of this study suggest that predictive temperamental factors for success in baseball players include traits of novelty seeking and reward dependence.

Psychiatry Investig 2015;12(4):459-465
\end{abstract}

Key Words Korean professional baseball players, Temperament and Character Inventory, Success, Anxiety.

\section{INTRODUCTION}

Several studies report that only exceptionally talented people break through the very narrow gates of becoming professional major league baseball players. ${ }^{1-5}$ Exceptional talent requires highly coordinated units, including physical, emotional, and mental components in individuals. Accordingly, a player who seeks maximum performance in a professional sports arena should possess a mental-emotional structure which enhances this physical development. ${ }^{6}$ In baseball, which is a competitive sport, a player's level of performance is determined by a complex set of variables involving certain characteristics of the play-

Received: November 26, 2014 Revised: December 24, 2014 Accepted: January 5, 2015 Available online: September 30, 2015

$\triangle$ Correspondence: Doug Hyun Han, MD, PhD

Department of Psychiatry, Chung-Ang University Hospital, 102 Heukseok-ro, Dongjak-gu, Seoul 06973, Republic of Korea

Tel: +82-2-6299-3132, Fax: +82-2-6299-1114, E-mail: hduk@yahoo.com

(a) This is an Open Access article distributed under the terms of the Creative Commons Attribution Non-Commercial License (http://creativecommons.org/licenses/bync/3.0) which permits unrestricted non-commercial use, distribution, and reproduction in any medium, provided the original work is properly cited. er such as fitness, technique (coordination abilities and kinetic skillfulness), tactics (cognitive and planning abilities), and psychological factors (personality and level of motivation). ${ }^{7}$ In particular, the personalities and characters of athletes have been regarded as crucial determinants of the athlete's performance and goals. ${ }^{8}$ Numerous studies suggest that personality is considered to be an important predictor of long-term success in professional sports. ${ }^{69-12}$ In addition, factors of personality and character are thought to reflect genetic and epigenetic influences on behaviors and predictable behaviors of individuals in response to perceived world and social stimuli. ${ }^{13-15}$ Consequently, the concept of an individual's "traits" describes the predisposition of individuals to react and to behave predictably to a variety of occurrences in their lives. ${ }^{16,17}$ Vanden Auweele et al. ${ }^{18}$ assert that the predictable behavior functionality of athletes is particularly important in sports psychology, thereby justifying studies that attempt to distinguish athletes from control populations. In addition, personality and sports have been further linked in the context of a player's position on a team and their level of performance in the game. ${ }^{15}$ In this context 
of differences between professional athletes and control groups, athletes display higher emotional stability, extroversion and self-confidence, as well as higher mental resistance, in comparison to non-athletes. Previous studies report a positive correlation between sports performance, extroversion and conscientiousness, and a negative correlation between sports performance and neuroticism. ${ }^{11,19}$

Anxiety is known to be correlated with personality-most prominently with neuroticism-but also with extroversion. ${ }^{2,20}$ A Temperament and Character Inventory (TCI)-based study by Parmigiani et al. ${ }^{21}$ indicates that among players of competitive sports, winners with higher levels of novelty seeking traits and lower levels of harm avoidance traits score significantly lower than losers on trait anxiety scales, as measured by the State-Trait Anxiety Inventory-Y (STAI-Y). Athletes with a greater number of anxious traits have a higher probability of losing to the competition. Several clinical studies report that high levels of harm avoidance characterize individuals with high levels of shyness and anxiety, and these traits are particularly evident in anxiety disorders. ${ }^{22,23}$

The TCI measures four higher-order personality dimensions, as defined by. ${ }^{24,25}$ The temperament traits are defined in terms of individual differences in associative learning in response to areas of novelty, danger or punishment, and reward. ${ }^{25}$ The inventory is used to analyze the temperamental traits (and associated behaviors) of novelty seeking (NS), harm avoidance (HA), reward dependence (RD) and persistence. Generally, the risk-taking and exploratory features of NS are often highlighted. However, there are also several factors of NS that may be described as self-regulatory skills, such as limiting impulsivity. ${ }^{26}$ On the other hand, harm avoidance is related to the inhibition or cessation of behaviors, passive avoidance, shyness of strangers, and rapid fatigability. Reward dependence $(\mathrm{RD})$ is related to the maintenance or continuation of ongoing behaviors, sentimentality, and social attachment. In previous sports-based personality studies, Han et al. ${ }^{27}$ compared groups of highly-skilled athletes and less-skilled athletes in a sample of high school students. The author ${ }^{27}$ reported that the levels of novelty seeking and reward dependence traits of the highly-skilled athletes were higher than the levels of these traits among the less-skilled athletes, but that the differences in novelty seeking traits were not statistically different between the groups. In a subsequent study comparing winners and losers, winners scored significantly higher than losers in the area of novelty seeking, while losers scored significantly higher than winners in areas of harm avoidance, reward dependence and persistence. ${ }^{21}$

In this five-year cohort study designed to investigate factors of temperament and character in professional baseball players predict the speed of obtaining success and the quality of suc- cess (i.e., achieving major league status), as well as anxiety control among athletes.

\section{METHODS}

\section{Participants}

Participants included 120 rookie baseball players and 107 age-matched and sex-matched non-players who were all boys in department of sports science from Chung Ang University and were no history of playing baseball. From 2004 to 2014, we have observed the status and career of baseball players who were agreed to participate in current research. All the rookies were players in the Korea Baseball Organization (KBO) during one of five seasons: 2004, 2005, 2008, 2009, or 2010. Two professional KBO teams select 20-30 amateur players from high school and university baseball teams on an annual basis. Of 129 rookie players on the two professional baseball teams, 120 players agreed to participate in our survey. To collect data, we processed interview with each player when they participated in the their spring camps. In accordance with rookie draft reports published by the $\mathrm{KBO}$, all the players were classified into two groups, including 21 higher-ranking players (the top $10 \%$ of drafted players) and 99 general players (the remaining $90 \%$ of players who were not ranked in the top $10 \%$ of each season's draft). Further classification involved a "starter" group ( $n=21)$, which included players who made the starting roster of a major league team during their rookie season, and a "non-starter" group ( $n=99)$, which included the players who failed to make the starting roster of a major league team during their rookie season. The "success" group $(n=35)$ included players with 396 plate appearances or 128 innings over 128 major league games in each season (full time major leager) during the full five seasons in our study (2014, Korean Baseball Rules, Korea Baseball Organization). The "non-success" group ( $n=85)$ included players who failed to make the roster of any major league team throughout the five seasons. The protocol of this study was approved by the Chung Ang University Institutional Review Board. Also, written informed consent was provided by all the participating players.

\section{Measures}

\section{Trait analysis}

The Korean version of the Temperament and Character Inventory (TCI) was used for trait analysis. ${ }^{28}$ The inventory consists of 240 items of true or false questions to evaluate four dimensions of temperament and three dimensions of character. The Cronbach's $\alpha$ and test-retest reliability of TCI have been previously reported as 0.77 and 0.81 , respectively. ${ }^{28}$ 


\section{Anxiety analysis}

The Korean version of the State-Trait Anxiety Inventory-Y (STAI-KY) was used to estimate state and trait anxiety levels among participants. ${ }^{29}$ This scale includes a total of 40 items, 20 of which describe trait anxieties, and 20 items that describe state anxieties. The Cronbach's $\alpha$ of STAI-KY is 0.91 for state and 0.82 for trait anxieties.

\section{Analysis and statistics}

Demographic characteristics including age, years of participation in sports, years of education, and state/trait anxiety were analyzed with ANOVA. Draft ranking was analyzed with independent t-tests. Starter/Non-starter, success/Non-success, and positions were analyzed with chi-squared tests. The comparisons of TCI and state-trait anxieties were as follows. At first, TCI scores and anxiety scores between baseball players and general people were analyzed with ANCOVA tests, controlling for age and years of education. Second, TCI scores and anxiety scores between the higher-ranking players and general players were analyzed with ANCOVA tests, controlling for age, years of participation in sports, and years of education. Third, TCI scores and anxiety scores between the starter and non-starter groups of players were analyzed with ANCOVA tests, controlling for age, years of participation in sports, and years of education. Finally, TCI scores and anxiety scores between the success and non-success groups were analyzed with ANCOVA tests, controlling for age, years of participation in sports, and years of education. In the comparison of demographic characteristics, statistical significance was set at two-tailed $\mathrm{p}<0.05$. In the comparison of TCI traits, statistical significance was set at two-tailed $\mathrm{p}<0.05 / 7$ (0.007). All analyses were conducted with the Statistical Package for the Social Sciences (SPSS) software package version 18.0.

\section{RESULTS}

\section{Demographic characteristics}

There were no significant differences in demographic variables between the players and non-players with regard to age, years of participating in sports, or years of education (Table 1). Also, there were no significant differences in demographic variables between the higher-ranking players and general players, starter and non-starter groups during the rookie season, and success and non-success groups over the course of five years (Table 1, 2, and 3).

\section{Comparison of TCI scores and anxiety scores between professional baseball players and non-players}

At a trend level, scores for traits of novelty seeking (18.08 \pm $4.92, \mathrm{p}=023)$, reward dependence $(18.34 \pm 3.78, \mathrm{p}<0.001)$, per-

Table 1. Demographic characteristics in player and non-player

\begin{tabular}{lccc}
\hline & Player $(\mathrm{N}=120)$ & Non-player $(\mathrm{N}=107)$ & $\mathrm{t} / \mathrm{p}$ \\
\hline Age & $20.48(2.42)$ & $20.53(1.11)$ & $0.303 / 0.912$ \\
Sports/education years & $10.50(2.68)$ & $10.99(0.92)$ & $1.804 / 0.872$ \\
State anxiety & $36.01(9.96)$ & $38.84(9.6)$ & $2.177 / 0.872$ \\
Trait anxiety & $38.51(7.29)$ & $41.30(5.08)$ & $3.305 / 0.001^{*}$ \\
\hline
\end{tabular}

*statistically significant, means (SD)

Table 2. Demographic characteristics in high ranking players, general players, and general people

\begin{tabular}{|c|c|c|c|c|}
\hline & High ranking players $(\mathrm{N}=21)$ & General players $(\mathrm{N}=99)$ & General people $(\mathrm{N}=107)$ & $\mathrm{F}, \mathrm{t}$ \\
\hline Age & $19.76(2.07)$ & $20.63(2.47)$ & $20.56(1.11)$ & $\mathrm{F}=1.87 / 0.157$ \\
\hline Sports/education years & $9.86(1.93)$ & $10.64(2.8)$ & $10.99(0.92)$ & $\mathrm{F}=2.91 / 0.057$ \\
\hline Draft ranking & $19.67(21.85)$ & $56.25(28.76)$ & - & $\mathrm{t}=5.50 / 0.018^{*}$ \\
\hline State anxiety & $28.67(10.91)$ & $37.56(9.06)$ & $30.22(8.75)$ & $\mathrm{F}=19.744 /<0.001^{*}$ \\
\hline Trait anxiety & $36.38(9.71)$ & $38.96(6.65)$ & $41.3(5.08)$ & $\mathrm{F}=6.949 / 0.001^{*}$ \\
\hline
\end{tabular}

*statistically significant, means (SD)

Table 3. Demographic characteristics in starter and non-starter

\begin{tabular}{|c|c|c|c|}
\hline & Starter $(\mathrm{N}=21)$ & Non-starter $(\mathrm{N}=99)$ & $\mathrm{t} / \mathrm{p}$ \\
\hline Age & $19.76(2.07)$ & $20.64(2.47)$ & $1.51 / 0.049^{*}$ \\
\hline Sports/education years & $9.86(1.93)$ & $10.64(2.78)$ & $1.21 / 0.051$ \\
\hline Draft ranking & $19.67(21.85)$ & $5.6 .26(28.76)$ & $5.5 / 0.018^{*}$ \\
\hline State anxiety & $28.66(10.91)$ & $37.56(9.06)$ & $3.94 / 0.503$ \\
\hline Trait anxiety & $36.38(9.71)$ & $38.96(6.65)$ & $1.48 / 0.005^{*}$ \\
\hline
\end{tabular}

*statistically significant, means (SD) 
sistence $(6.01 \pm 1.43, \mathrm{p}<0.001)$ and cooperativeness $(30.38 \pm 5.55$, $\mathrm{p}<0.001)$ in professional baseball players were higher than the scores for these traits in non-players (Table 4). The state and trait anxiety scores in professional baseball players were lower than these scores in non-players $(\mathrm{F}=4.74, \mathrm{p}=0.03 ; \mathrm{F}=10,92$, $\mathrm{p}=0.001$ ) (Table 4).

\section{Comparison of TCI scores between higher-ranking players and general players}

There was no statistical significance in differences of age, sports carrier, and years of education between higher-ranking players and general players. Of the higher-ranking players, 85.7\% had experience on a starting roster during their rookie season, while $28.3 \%$ of general players had experience on a starting roster as rookies. Of the higher-ranking players, 54.3\% had experience as full-time major leaguers (i.e., our definition of success), while $2.4 \%$ of general players had experience as full-time major leaguers during the full five years of this study (Table 1,2, and 3). State anxiety scores in higher-ranking players were lower than these scores in general players and nonplayers (Table 1,2, and 3).

\section{Comparison of TCI and anxiety scores between the starter and non-starter groups}

Among the player groups, the novelty seeking scores of the starter group were higher than those of the non-starter group (i.e., starter vs. non-starter: $22.67 \pm 4.81$ vs. $17.11 \pm 4.39, \mathrm{p}<0.001$ ) (Table 5). The state anxiety scores of the starter group were lower than those of the non-starter group $(\mathrm{F}=15.52, \mathrm{p}<0.001)$ (Table 5).

\section{Comparison of TCI scores between the success and non-success groups}

Among the player groups, scores for the trait of reward dependence were higher in the success group than those in the non-success group at a trend level (i.e., success vs. non-success: $19.66 \pm 3.15$ vs. $17.8 \pm 3.9, \mathrm{p}<0.01$ ) (Table 6 ). The novelty seeking scores of the success group were higher than those of the non-success group $(\mathrm{F}=3.737, \mathrm{p}=0.056)$ (Table 6).

\section{Correlation of anxiety levels and scores of TCI}

In all the athlete groups, trait anxieties were correlated with state anxieties $(\mathrm{r}=0.30 ; \mathrm{p}<0.01)$. In the non-starter group, re-

Table 4. Comparison of Temperament and Character Inventory between players and non-players

\begin{tabular}{llcccc}
\hline & & Players $(\mathrm{N}=120)$ & General people $(\mathrm{N}=107)$ & $\mathrm{F}$ & \multicolumn{2}{c}{$\mathrm{p}$} \\
\hline TCI & NS & $18.08(4.92)$ & $19.77(4.02)$ & 5.278 & $0.023^{*}$ \\
& HA & $13.28(5.82)$ & $14.59(4.97)$ & 2.19 & 0.140 \\
& RD & $18.34(3.78)$ & $15.22(3.21)$ & 32.086 & $<0.001^{* * *}$ \\
& P & $6.01(1.43)$ & $4.82(1.6)$ & 26.371 & $<0.001^{* * *}$ \\
& SD & $23.19(9.91)$ & $22.52(6.03)$ & 0.931 & 0.336 \\
& CO & $30.38(5.55)$ & $27.89(5.54)$ & 12.813 & $<0.001^{* * *}$ \\
& ST & $15.21(6.04)$ & $15.87(5.41)$ & 0.097 & 0.756 \\
& State ANX & $36.01(9.96)$ & $38.84(9.6)$ & 4.739 & $0.031^{*}$ \\
& Trait ANX & $38.51(7.29)$ & $41.3(5.08)$ & 10.924 & $0.001^{* * *}$ \\
\hline
\end{tabular}

${ }^{*} \mathrm{p}<0.05,{ }^{* * *} \mathrm{p}<0.001$, data are means $( \pm \mathrm{SD})$. TCI: Temperament and Character Inventory, NS: novelty seeking, HA: harm avoidance, RD: reward dependence, P: persistence, SD: self-directedness, CO: cooperativeness, ST: self-transcendence, ANX: anxiety

Table 5. Comparison of Temperament and Character Inventory between starter and non-starter of players

\begin{tabular}{|c|c|c|c|c|c|}
\hline & & Starter $(\mathrm{N}=21)$ & Non-starter $(\mathrm{N}=99)$ & $\mathrm{F}$ & $\mathrm{p}$ \\
\hline \multirow[t]{7}{*}{ TCI } & NS & $22.67(4.81)$ & $17.11(4.39)$ & 21.223 & $<0.001^{*}$ \\
\hline & HA & $13.05(5.38)$ & $13.33(5.93)$ & 0.102 & 0.75 \\
\hline & $\mathrm{RD}$ & $19.43(3.70)$ & $18.11(3.8)$ & 3.652 & 0.059 \\
\hline & $\mathrm{P}$ & $6(1.38)$ & $6.01(1.45)$ & 0.133 & 0.716 \\
\hline & $\mathrm{SD}$ & $21.24(10.81)$ & $23.61(9.72)$ & 0.614 & 0.435 \\
\hline & $\mathrm{CO}$ & $30.43(5.23)$ & $30.37(5.65)$ & 0.053 & 0.819 \\
\hline & ST & $15.24(4.41)$ & $15.2(6.36)$ & 0.021 & 0.886 \\
\hline \multirow[t]{2}{*}{ STAI-Y } & State ANX & 28.67 (10.9) & $37.56(9.06)$ & 15.52 & $<0.001^{*}$ \\
\hline & Trait ANX & $36.38(9.71)$ & $38.96(6.65)$ & 2.187 & 0.142 \\
\hline
\end{tabular}

${ }^{*} \mathrm{p}<0.001$, data are means $( \pm \mathrm{SD})$. TCI: Temperament and Character Inventory, NS: novelty seeking, HA: harm avoidance, RD: reward dependence, P: persistence, SD: self-directedness, CO: cooperativeness, ST: self-transcendence, ANX: anxiety 
ward dependence scores were correlated with state anxiety scores $(r=0.30 ; p<0.01)$ (Table 7$)$. In the success group, novelty seeking scores were negatively correlated with state anxiety scores $(r=-0.34 ; p<0.05)$. In the non-success group, reward dependence scores were correlated with both state and trait anxiety scores $(\mathrm{r}=0.34 ; \mathrm{p}<0.01)$ (Table 7).

\section{DISCUSSION}

To the best of our knowledge, this is the first study to follow the careers of rookie players in two professional KBO baseball teams for a period of five years.

Not surprisingly, a greater number of higher-ranking players were registered on major league rosters in comparison to general players in each of their years as players in the professional baseball league in Korea. In addition, a greater number of higher-ranking players were full-time major leaguers in comparison to general players. One intriguing result of this study, however, concerns our analysis of the temperament and characters of the athletes, which shows that starting players in the professional baseball league have higher levels of novelty seeking traits than non-starters. Novelty seeking is hypothesized to be a heritable tendency toward intense exhilaration or excitement in response to novel stimuli or cues for potential rewards. ${ }^{25}$ As one factor of an individual's temperament, novelty seeking is correlated with extroversion. ${ }^{30}$ Recent studies of extroversion in athletes report that professional athletes are more extroverted than average players of competitive sports. ${ }^{31,32}$ An athlete's level of extroversion can be improved with the achievement of goals and success in sporting activities. ${ }^{33}$ In addition, individuals with higher novelty seeking traits are characterized by the ability to regulate a broad band of goal-seeking behaviors

Table 6. Comparison of Temperament and Character Inventory between groups of success and non-success

\begin{tabular}{|c|c|c|c|c|c|}
\hline & & Success group $(\mathrm{N}=35)$ & Non-success group $(\mathrm{N}=85)$ & $\mathrm{F}$ & $\mathrm{p}$ \\
\hline \multirow[t]{7}{*}{ TCI } & NS & $19.81(5.23)$ & $17.3(4.64)$ & 3.737 & 0.056 \\
\hline & $\mathrm{HA}$ & $12.88(5.91)$ & $13.44(5.81)$ & 0.206 & 0.651 \\
\hline & $\mathrm{RD}$ & $19.66(3.15)$ & $17.80(3.92)$ & 7.735 & $0.006^{*}$ \\
\hline & $\mathrm{P}$ & $6.23(1.26)$ & $5.92(1.53)$ & 1.868 & 0.174 \\
\hline & SD & $21.94(10.9)$ & $23.71(9.52)$ & 0.0520 & 0.821 \\
\hline & $\mathrm{CO}$ & $31.03(5.53)$ & $30.11(5.58)$ & 0.814 & 0.369 \\
\hline & ST & $13.97(5.31)$ & $15.71(6.28)$ & 2.343 & 0.129 \\
\hline \multirow[t]{2}{*}{ STAI-Y } & State anxiety & $32.17(10.87)$ & $37.59(9.16)$ & 7.760 & $0.006^{*}$ \\
\hline & Trait anxiety & $37.03(8.16)$ & $39.12(6.87)$ & 2.048 & 0.155 \\
\hline
\end{tabular}

*statistically significant, data are means $( \pm \mathrm{SD})$. TCI: Temperament and Character Inventory, NS: novelty seeking, HA: harm avoidance, RD: reward dependence, P: persistence, SD: self-directedness, CO: cooperativeness, ST: self-transcendence, STAI-Y: State and Trait Anxiety Inventory

Table 7. Correlation between anxiety levels and $\mathrm{TCl}$

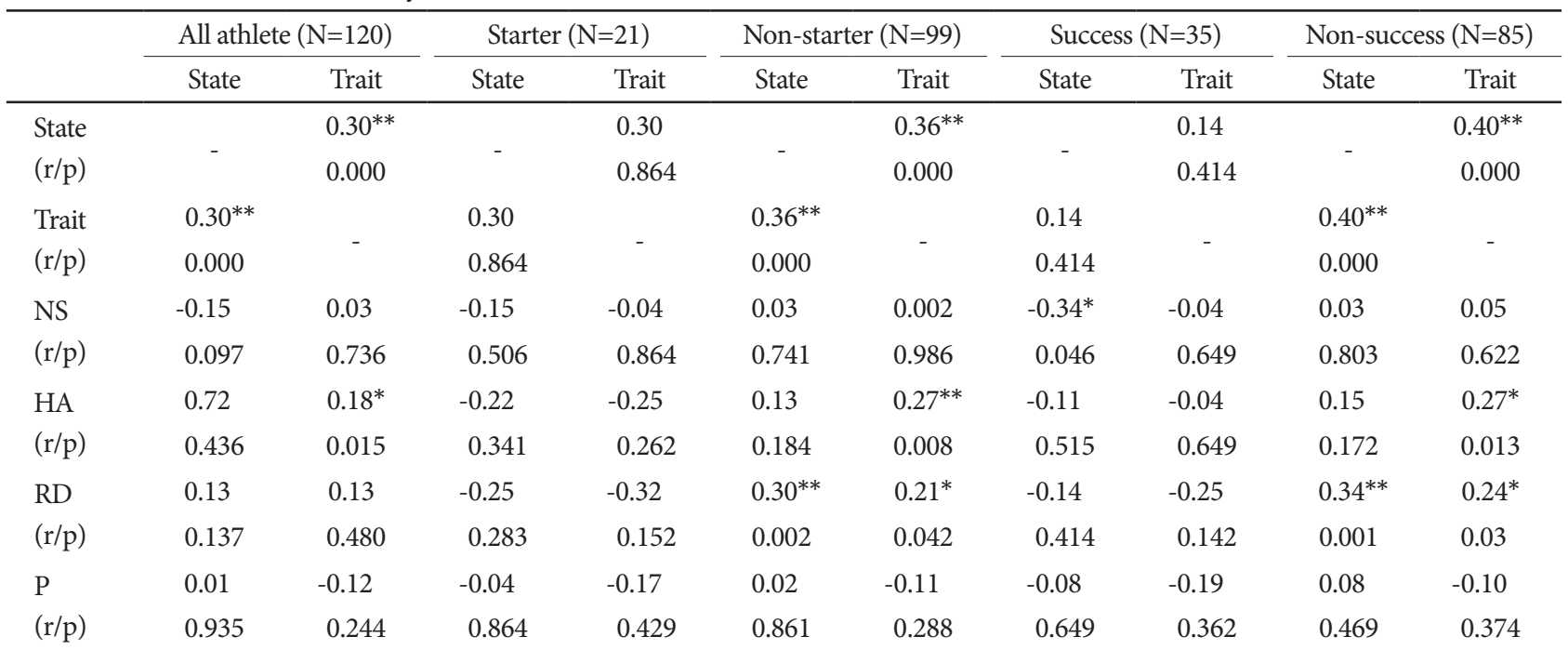

${ }^{*} \mathrm{p}<0.05,{ }^{* *} \mathrm{p}<0.01$. TCI: Temperament and Character Inventory, State: state anxiety, Trait: trait anxiety, NS: novelty seeking, HA: harm avoidance, $\mathrm{RD}$ : reward dependence, P: persistence 
and motivation, including positive affectivity, energy, and attention. ${ }^{34}$ Interestingly, NS scores of the success group were negatively corrected with the state anxiety scores of these players in the current study. Individuals with higher NS scores are characterized as having hyperthymic temperaments in terms of extroversion, sociability, and activeness. ${ }^{35}$ Doherty and Nugent ${ }^{36}$ suggested that personal traits including sociability, extraversion, openness, and self-esteem were associated with academic success in medical school students. Therefore, NS scores may be an important temperamental indicator for the more rapid achievement of major leaguer title in Korean rookie baseball players.

Reward dependence scores of the success group were higher than those of the non-success group. Characteristics of individuals with high levels of reward dependence include persistence, industriousness, sensitivity to social cues and social support, as well as the ability to delay gratification with the expectation of eventually being rewarded. ${ }^{37} \mathrm{~A}$ study by Cloninger et al. ${ }^{30}$ suggests that the RD score represents the sensitivity of a person who is highly stimulated by social rewards. The work of Brock et al. ${ }^{38}$ reports that a high ability to delay gratification involves persistence, conscientiousness, and endurance, which may influence emotions, motivations, and goal-directed behaviors under challenging circumstances. Therefore, RD may be associated with long-term success (major leaguer not at first season but second season after ) in Korean rookie baseball players.

In the results of this study, reward dependence in the nonsuccess group was correlated with state anxiety, while state anxiety was not associated with RD in the success group herein. Moreover, state anxiety in the success group was correlated with the NS scores of players. The meaning of correlation between $\mathrm{RD}$ and anxiety was associated with the success of players in current results.

Individuals with higher levels of reward dependence are characterized as being eager to please others, warmly sympathetic, and dependent on others. ${ }^{25}$ A study by Robazza and Bortoli ${ }^{39}$ report that non-elite athletes report higher levels of cognitive and somatic anxiety symptoms, and experience these symptoms as more debilitative than elite athletes do. Taken together, players in the non-success group may treat anxiety with the help of other people, while the players in the success group may treat anxiety with persistence, industriousness, and delay gratification with the expectation of eventually being rewarded.

There were several limitations in current study. First, due to the small number of subjects comprising our study, we are unable to generalize the results of the current research. The number of athletes in the success group was less than 30 . Second, because this study does not assess the clinical characteristics associated with the personality traits herein, we are limited to speculation about them based on the conclusions of previous studies.

\section{Conclusions}

Based on the results of the current research, predictive personality factors for successful careers in major league baseball are the traits of novelty seeking and reward dependence. Novelty seeking traits are associated with the rapid achievement of success, and $\mathrm{RD}$ traits are associated with long-term success among aspiring professional baseball players in Korea.

\section{Acknowledgments}

This study was supported by the Korea Creative Content Agency under Grant (R2014040055).

\section{REFERENCES}

1. Brustad RJ. Affective outcomes in competitive youth sport: the influence of intrapersonal and socialization factors. J Sport Exerc Psychol 1988;10:307-321.

2. Costa PT, McCrae RR. Influence of extraversion and neuroticism on subjective well-being: happy and unhappy people. J Pers Soc Psychol 1980;38:668-678.

3. Benjamin SB. Developing Talent in Young People. New York: Ballantine Books; 1985.

4. Hellstedt JC. The coach/parent/athlete relationship. Sport Psychol 1987;1:151-160.

5. Hellstedt JC. Invisible players: a family systems model. Clin Sports Med 2005;24:899-928.

6. La Place JP. Personality and its relationship to success in professional baseball. Research quarterly. Am Assoc Health Physic Educ Recreat 1954;25:313-319.

7. Lee SC, Wang CC, Huang CC, Wang JS, Huang CH, Chen CY, et al. The idolization of Chien-Ming Wang and social psychological factors in Taiwan. Int J Phys Sci 2011;6:2607-2612.

8. Hoyt AL, Rhodes RE, Hausenblas HA, Giacobbi Jr PR. Integrating five-factor model facet-level traits with the theory of planned behavior and exercise. Psychol Sport Exerc 2009;10:565-572.

9. Allen MS, Greenlees I, Jones M. An investigation of the five-factor model of personality and coping behaviour in sport. J Sport Sci 2011;29: 841-850.

10. Peterson SL, Weber JC, Trousdale WW. Personality traits of women in team sports vs. women in individual sports. Res Q 1967;38:686-690.

11. Rushall BS. The status of personality research and application in sports and physical education. J Sports Med Phys Fitness 1973;13:281-290.

12. Valliant PM, Bennie FA,Valiant JJ. Do marathoners differ from joggers in personality profile: a sports psychology approach. J Sports Med Phys Fitness1981;21:62-67.

13. Allport GW. The open system in personality theory. J Abnorm Soc Psychol 1960;61:301-310.

14. Cattell RB, Rao DC, Schuerger JM, Vaughan DS. Unitary personality source traits analyzed for heritability. Hum Hered 1981;31:261-275.

15. Eysenck HJ. The organization of personality. J Pers 1951;20:101-117.

16. Allik J. Personality dimensions across cultures. J Pers Disord 2005;19: 212-232.

17. Hampson SE, Goldberg LR. A first large cohort study of personality trait stability over the 40 years between elementary school and midlife. J Pers Soc Psychol 2006;91:763-779.

18. Vanden Auweele YN, Kurt RR, Van MV. Personality and the Athlete, 2nd Edition. New York: Wiley, 2001, p.251-272.

19. Saklofske DH, Austin EJ, Rohr BA, Andrews JJ. Personality, emotional intelligence and exercise. J Health Psychol 2007;12:937-948.

20. Middeldorp CM, Cath DC, van den Berg M, Beem AL, Van Dyck R. 
Boomsma DI. The Association of Personality with Anxious and Depressive Psychopathology. In: Canli T, Editor. Biology of Personality and Individual Differences. 12th Edition. New York: Guilford, 2006, p.251-272.

21. Parmigiani S, Dadomo H, Bartolomucci A, Brain PF, Carbucicchio A, Costantino $\mathrm{C}$, et al. Personality traits and endocrine response as possible asymmetry factors of agonistic outcome in karate athletes. Aggress Behav 2009;35:324-333.

22. Faytout M, Tignol J, Swendsen J, Grabot D, Aouizerate B, Lepine JP. Social phobia, fear of negative evaluation and harm avoidance. Eur Psychiatry 2007;22:75-79.

23. Marteinsdottir IT, Maria FT, Anderberg UM, Ekselius L. Personality dimensions measured by the Temperament and Character Inventory (TCI) in subjects with social phobia. Nord J Psychiatry 2003;57:29-35.

24. Cloninger CR. A unified biosocial theory of personality and its role in the development of anxiety states. Psychiatr Dev 1986;4:167-226.

25. Cloninger CR. A systematic method for clinical description and classification of personality variants. A proposal. Arch Gen Psychiatry 1987;44: 573-588.

26. Rettew DC, Stanger CM, Laura DA, Hudziak JJ. Interactions between child and parent temperament and child behavior problems. Compr Psychiatry 2006;47:412-420.

27. Han DH, Kim JH, Lee YS, Bae SJ, Bae, SJ, Kim HJ, et al. Influence of temperament and anxiety on athletic performance. J Sports Sci Med 2006; 5:381-389.

28. Sung SM, Kim JH, Yang EJ, Abrams KY, Lyoo IK. Reliability and validity of the Korean version of the Temperament and Character Inventory. Compr Psychiatry 2002;43:235-243.

29. Cho SC. Assessment of test anxiety. J Korean Neuropsychiatr 1989;28: 668-677.

30. Cloninger CR, Przybeck TR, Svrakic DM. The tridimensional personal- ity questionnaire: US normative data. Psychol Rep 1991;69:1047-1057.

31. Filho MGB, Ribeiro LCS, García FG. Comparison of personality characteristics between high-level Brazilian athletes and non-athletes. Brasileira de Medicina do Esporte 2005;11:114e-118e.

32. Malinauskas R, Dumciene A, Mamkus G, Venckunas T. Personality traits and exercise capacity in male athletes and non-athletes. Percept Mot Skills 2014;118:145-161.

33. Egloff B, Jan Gruhn A. Personality and endurance sports. Pers Indiv Differ 1996;21:223-229.

34. Winters R., Scott W, Beevers C. In: Johnson A, Hayes T, Field, PM, Editors. Schneiderman N. Affective Distress as a Central and Organizing Symptom in Depression: Neurobiological Mechanisms. Stress, Coping, and Depression. Mahweh, NJ: Lawrence Erlbaum, 2000, p.177-219.

35. Maremmani I, Akiskal HS, Signoretta S, Liguori A, Perugi G, Cloninger R. The relationship of Kraepelian affective temperaments (as measured by TEMPS-I) to the tridimensional personality questionnaire (TPQ). J Affect Dis 2005;85:17-27.

36. Doherty EM, Nugent E. Personality factors and medical training: a review of the literature. Med Educ 2011;45:132-140.

37. Cloninger CR, von Knorring AL, Sigvardsson S, Bohman M. Symptom patterns and causes of somatization in men: II. Genetic and environmental independence from somatization in women. Genet Epidemiol 1986;3:171-185.

38. Brock LL, Rimm-Kaufman SE, Wanless SB. Delay of gratification in first grade: the role of instructional context. Learn Individ Differ 2014;29:8188.

39. Robazza C, Bortoli L. Intensity, idiosyncratic content and functional impact of performance-related emotions in athletes. J Sports Sci 2003;21: 171-189. 